\title{
Accuracy assessments of MTBS and AFS 30m resolution burned area products
}

\author{
Zhaoming Zhang a , Guojin He ${ }^{\text {a,* }}$, Tengfei Long ${ }^{\text {a }}$, Mengmeng Wang a, Guizhou Wang a , Xiaomei Zhang a \\ ${ }^{\text {a }}$ Institute of Remote Sensing and Digital Earth, Chinese Academy of Sciences, Beijing100094, China \\ *Corresponding Author: hegj@ radi.ac.cn
}

\begin{abstract}
Accurate and complete data on fire locations and burned areas are important for a variety of applications. Imagery collected by the family of Landsat sensors is useful and appropriate for monitoring the extent of area burned, and provide spatial and temporal resolutions ideal for science and management applications. In recent years, the Monitoring Trends in Burn Severity Project (MTBS) provided consistent, 30 meter resolution burn severity and perimeters of fires across the United States from 1984-2015 based on Landsat imagery; Australia released its Fire Scars (AFS) products derived from all available Landsat 5, 7 and 8 images. Both 30 meter burned area products can be freely accessed from the website. However, to date, there currently lacks an independent validation to the MTBS and AFS products. In this paper, a study was performed to validate these two 30 meter burned area products. Validation data covered a range of ecosystems and fire regimes, and the acquisition time of the validation data were in different seasons and spanned from 1980s to 2010s. It was found that the accuracy of the MTBS burned area products ranged from $76.67 \%$ to $100 \%$, and the average accuracy was $97.24 \%$. While the AFS product accuracy ranged from $25.71 \%$ to $100 \%$, with average accuracy of $81.75 \%$.
\end{abstract}

Keywords: satellite remote sensing, Landsat, burned area.

\section{Introduction}

Burned area is an important parameter for carbon cycling and global change studies in satellite remote sensing community. Up to now, there is no Landsat based global burned area product yet, however, some regional Landsat burned area products have been publicly released in recent years. Australia released its Fire Scars (AFS) products derived from all available Landsat 5, 7 and 8 images using time series change detection technique ${ }^{(1)}$. Fire scars are automatically detected and mapped using dense time series of Landsat imagery acquired over the period 1987 - 2015 and the AFS product only covers the state of Queensland, Australia. Monitoring Trends in Burn Severity (MTBS) project, sponsored by the Wildland Fire Leadership Council (WFLC) provided consistent, 30 meter resolution burn severity data and fire perimeters across all lands of the United States from 1984-2015(2). MTBS products are generated based on the difference of Normalized Burned Ratio (NBR) calculated from pre-fire and post-fire images; products generation relies on manually mapping. The Burned Area Essential Climate Variable (BAECV), developed by the U.S. Geological Survey (USGS), produced Landsat derived burned area products across the conterminous United States (CONUS) from 1984-2015, and its products have been released in April $2017^{(3)}$.Main differences between the MTBS and BAECV is the BAECV products are automatically generated based on all available Landsat images. Shortly after the release of the BAECV products, Vanderhoof et al. (4) performed a validation to this product and gave an overall evaluation of its accuracy. However, to date, there currently lacks an independent validation to the MTBS and AFS products. This study is designed to carry out accuracy validation to these two 30 meter burned area products.

\section{Methodology description}

While Landsat is often used to validate the coarse resolution products (e.g. AVHRR or MODIS), for Landsat science products, no such regularly collected, long-term source of higher resolution satellite imagery exists, 
complicating the validation of these products. In this study, accuracy validation were performed in support of random sampling and expert decision. Both the MTBS and AFS products are monthly products. To verify the MTBS and AFS products, 29 and 5 World Reference System, version 2 (WRS2) path/rows were selected across the CONUS and the state of Queensland, Australia, respectively. Path/row locations were spatially distributed in order to capture major ecosystems and differences in their fire regimes, with more path/rows selected in areas where fires more frequently occur (the under-laid burned area distribution map were generated by compositing the monthly MTBS and AFS products). The acquisition time of the path/rows were in different seasons and spanned from 1980s to 2010s. Sample points were collected randomly across the Landsat imagery. One half of the random sampling points locations were located within MTBS/AFS burned area perimeters and attributes from each fire were assigned to the points. The other half sampling points were randomly located outside of the burned area perimeters. Sampling points were interpreted by three independent experts who have abundant experiences in burned area recognition and the points were identified as burned if at least two of the three experts agreed.

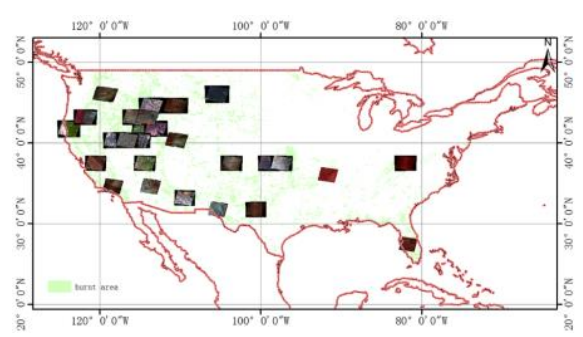

Fig.1 selected path/rows for MTBS product

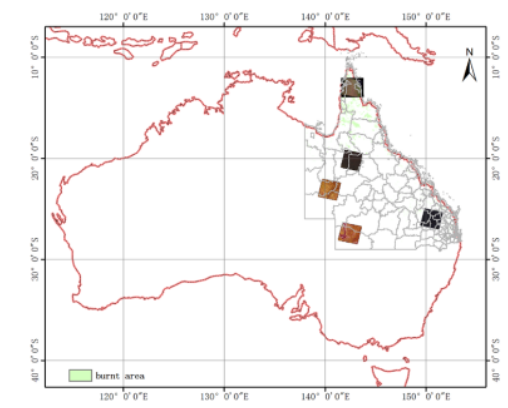

Fig.2 selected path/rows for AFS product

\section{Results and discussion}

Accuracy validation results of the MTBS and AFS products are displayed in table 1 and table 2, respectively. As table 1 shows, accuracy of the MTBS burned area products ranged from $76.67 \%$ to $100 \%$, with the average accuracy of $97.24 \%$. We can learn from table 2 that accuracy of the AFS burned area products ranged from $25.71 \%$ to $100 \%$, and the average accuracy was $81.75 \%$. Goodwin and Collett ${ }^{(1)}$ developed the AFS algorithm for mapping fire history captured in Landsat time series across Queensland, Australia, and they also conducted accuracy evaluation to their algorithm. The evaluation results demonstrated an average producer's accuracy of $85 \%$ (range of 28 to $100 \%$ for individual images) and average user's accuracy of $71 \%$ (range of 4 to $99 \%$ for individual images). MTBS products were produced based on analysis of the difference of Normalized Burned Ratio (NBR) calculated from pre-fire and post-fire images; the MTBS dataset relies on manually mapping and human intervention, and achieved a high accuracy. Algorithm of the AFS product is fully automatic. Despite the advantages, automation can be expected to introduce errors in burned area generation, which may result to the lower accuracy and wider accuracy range of the AFS product. For automated approach, a possible way to improve its accuracy is using supervised machine learning approach, like the USGS Landsat BAECV burned area product, which achieved a relatively high and stable accuracy ${ }^{(4)}$. While such approach relies heavily on training samples as the primary source of observed burned and unburned areas to train and evaluate the algorithm, these training samples should have similar spatial resolution with the Landsat data. It is difficult to collect a sufficient number of high-quality training reference samples, especially for a large study area or long temporal studies.

Algorithm of the AFS product is fully automatic and some fixed thresholds were used in the production. When using fixed thresholds method, Landsat DN value must be converted to land surface reflectance or land surface temperature to ensure comparability between Landsat data acquired from different Landsat sensors, different places, and different dates. For AFS product, Landsat time series imagery was converted from DN to a standardised surface reflectance using the method of Flood et al. ${ }^{(5)}$. In this method, atmospheric effects due to high aerosol loadings were not removed as no operational method was available for accurately estimating aerosol loading/haze/smoke over much of Australia. However, aerosol absorption and scattering exert serious influences in the conversion process from satellite DN to land surface reflectance. Furthermore, for AFS algorithm, the DN stored in thermal infrared band $6 \quad(10.40-12.50 \mu \mathrm{m})$ was only converted to 
top-of-atmosphere brightness temperature, and no atmospheric correction for the thermal band was applied. Inaccurate preprocessing may be another reason for the relatively low accuracy of the AFS product. When the fixed threshold method is employed to derive large scale and long temporal burned area product, Landsat data must be processed to acquire real land surface reflectance (or land surface temperature) by considering a variety of influencing factors, including atmospheric scattering and absorption, topographic variations (shadow, slope, etc.), and Bi-Directional Reflectance Distribution Function (BRDF) effects. Landsat higher level science data products project launched by USGS aims to provide systematically consistent global scale land surface reflectance product, which may be a better choice as inputs to the threshold based burned area extraction algorithm.

Table 1. Validation results of the MTBS products

\begin{tabular}{|c|c|c|c|}
\hline $\begin{array}{c}\text { Acquisition } \\
\text { time }\end{array}$ & $\begin{array}{c}\text { Path/ro } \\
\text { w }\end{array}$ & $\begin{array}{c}\text { Points } \\
\text { Number }\end{array}$ & Accuracy \\
\hline Aug.1991 & 016041 & 50 & $100.00 \%$ \\
\hline Apr.1992 & 032038 & 46 & $100.00 \%$ \\
\hline Aug.1992 & 037032 & 41 & $100.00 \%$ \\
\hline Aug.1992 & 044028 & 42 & $97.62 \%$ \\
\hline Oct.1992 & 018034 & 43 & $100.00 \%$ \\
\hline Oct.1992 & 029038 & 48 & $100.00 \%$ \\
\hline Oct.1992 & 032034 & 47 & $100.00 \%$ \\
\hline Oct.1992 & 038029 & 44 & $100.00 \%$ \\
\hline Nov.1992 & 041036 & 45 & $100.00 \%$ \\
\hline Aug.1996 & 040030 & 50 & $98 \%$ \\
\hline June 1998 & 038036 & 41 & $100 \%$ \\
\hline Aug.1998 & 043034 & 46 & $93.48 \%$ \\
\hline Aug.1998 & 045030 & 50 & $100 \%$ \\
\hline Sep.1998 & 024035 & 49 & $100 \%$ \\
\hline Sep.1998 & 040030 & 47 & $100 \%$ \\
\hline Sep.1999 & 041032 & 50 & $98 \%$ \\
\hline Sep.1999 & 042032 & 50 & $100 \%$ \\
\hline Sep.1999 & 029034 & 30 & $76.67 \%$ \\
\hline Sep.1999 & 040032 & 50 & $96 \%$ \\
\hline Aug.2000 & 040029 & 50 & $98 \%$ \\
\hline Apr.2007 & 032038 & 48 & $100.00 \%$ \\
\hline June 2007 & 037032 & 50 & $100.00 \%$ \\
\hline Aug.2007 & 040031 & 50 & $94 \%$ \\
\hline Aug.2007 & 039031 & 50 & $98 \%$ \\
\hline Aug.2007 & 044028 & 47 & $100.00 \%$ \\
\hline Aug.2007 & 018034 & 46 & \\
\hline Sep.2007 & 038029 & 45 & $100 \%$ \\
\hline
\end{tabular}

\begin{tabular}{|c|c|c|c|}
\hline Oct.2007 & 032034 & 48 & $100.00 \%$ \\
\hline Oct.2007 & 029038 & 48 & $100.00 \%$ \\
\hline Nov.2007 & 041036 & 49 & $100.00 \%$ \\
\hline Feb.2008 & 016041 & 49 & $98.00 \%$ \\
\hline June 2011 & 035037 & 50 & $94 \%$ \\
\hline June 2011 & 028034 & 50 & $84 \%$ \\
\hline July 2011 & 039034 & 30 & $90 \%$ \\
\hline Mar.2013 & 038036 & 50 & $100 \%$ \\
\hline July 2013 & 045030 & 53 & $100 \%$ \\
\hline Sep.2013 & 024035 & 53 & $100 \%$ \\
\hline Sep.2013 & 040030 & 47 & $100 \%$ \\
\hline Sep.2013 & 043034 & 56 & $100 \%$ \\
\hline May 2014 & 035028 & 30 & $96.7 \%$ \\
\hline May 2014 & 028033 & 50 & $96 \%$ \\
\hline Aug.2014 & 046031 & 100 & $97 \%$ \\
\hline & & Average & $97.24 \%$ \\
\hline
\end{tabular}

During the validation process of this study, sampling points were interpreted by three independent experts who have abundant experiences in burned area recognition and the points were identified as burned if at least two of the three experts agreed. A similar method was used by Vanderhoof et al. ${ }^{(4)}$, and they found that errors could be minimized by using the rendition of the dataset in which pixels were mapped as burned if at least two of the three analysts agreed.

For satellite data product validation, a commonly used method is to employ higher spatial resolution satellite data. For example, in order to validate MODIS derived data product (1KM spatial resolution), Landsat satellite data is commonly used. Considering the long temporal range of Landsat data (1970s-present) and moderate to high spatial resolution, it is impossible to find regularly collected, long-term source of higher resolution satellite imagery to validate Landsat derived burned area product. Although the validation process was conducted by three independent experienced experts with great caution. However, relying on Landsat for both product generation and validation limits our ability to assess inaccuracies imposed by the satellite sensor itself, such as radiometric calibration accuracy, spectral band settings, geolocation and mixed pixels ${ }^{(6)}$.

\section{Conclusions}

Accuracy assessments of the MTBS and AFS 30m resolution burned area products were performed in this 
study. The MTBS product relies on manually mapping, and achieved a high accuracy, with accuracy ranging from $76.67 \%$ to $100 \%$ and average accuracy of $97.24 \%$. Algorithm of the AFS product is fully automatic and without human intervention. Despite the advantages, automation can be expected to introduce errors in burned area generation, and accuracy of the AFS product was lower than MTBS, with accuracy ranging from $25.71 \%$ to $100 \%$ and average accuracy of $81.75 \%$.

\section{Acknowledgment}

This research has been supported by The National Key Research and Development Program of China (2016YFA0600302 and 2016YFB0501502), and National Natural Science Foundation of China (61401461).

Table 2. Validation results of the AFS products

\begin{tabular}{|c|c|c|c|}
\hline $\begin{array}{c}\text { Acquisition } \\
\text { time }\end{array}$ & $\begin{array}{c}\text { Path/ro } \\
\text { w }\end{array}$ & $\begin{array}{c}\text { Points } \\
\text { Number }\end{array}$ & Accuracy \\
\hline Sep.1987 & 091078 & 50 & $83.33 \%$ \\
\hline Sep.1987 & 097074 & 39 & $100.00 \%$ \\
\hline Sep.1987 & 096079 & 42 & $100.00 \%$ \\
\hline Oct.1987 & 098076 & 38 & $100.00 \%$ \\
\hline Apr.1988 & 098069 & 50 & $86.00 \%$ \\
\hline Aug.1990 & 098069 & 30 & $76.67 \%$ \\
\hline Oct.1991 & 098069 & 41 & $80.49 \%$ \\
\hline Oct.1993 & 098069 & 40 & $65.00 \%$ \\
\hline June 1994 & 091078 & 30 & $100.00 \%$ \\
\hline Aug.1994 & 096079 & 44 & $100.00 \%$ \\
\hline Aug.1994 & 097074 & 37 & $100.00 \%$ \\
\hline Aug.1994 & 098076 & 41 & $100.00 \%$ \\
\hline July 1995 & 098069 & 43 & $53.49 \%$ \\
\hline Sep.1997 & 098069 & 40 & $50.00 \%$ \\
\hline June 2004 & 091078 & 27 & $96.30 \%$ \\
\hline July 2004 & 098069 & 35 & $25.71 \%$ \\
\hline July 2004 & 097074 & 37 & $100.00 \%$ \\
\hline Aug.2004 & 096079 & 31 & $100.00 \%$ \\
\hline Sep.2004 & 098076 & 44 & $100.00 \%$ \\
\hline Sep.2005 & 098069 & 45 & $68.89 \%$ \\
\hline Sep.2007 & 098069 & 39 & $53.85 \%$ \\
\hline June 2009 & 098069 & 38 & $47.37 \%$ \\
\hline Feb.2011 & 098069 & $38.58 \%$ \\
\hline June 2011 & 098069 & 40 & $81.00 \%$ \\
\hline Jan.2013 & 098069 & 41 & $80 \%$ \\
\hline July 2014 & 091078 & 28 & \\
\hline Aug.2014 & 098069 & 40 & $500 \%$ \\
\hline
\end{tabular}

\begin{tabular}{|c|c|c|c|}
\hline Aug.2014 & 096079 & 33 & $100.00 \%$ \\
\hline Aug.2014 & 097074 & 40 & $100.00 \%$ \\
\hline Aug.2014 & 098076 & 41 & $100.00 \%$ \\
\hline & & Average & $81.75 \%$ \\
\hline
\end{tabular}

\section{References}

(1) Goodwin N R, and Collett L J : "Development of an automated method for mapping fire history captured in Landsat TM and ETM+ time series across Queensland, Australia”, Remote Sensing of Environment, Vol. 148, pp. 206-221, 2014

(2) Eidenshink J, Schwind B and Brewer K : "A project for monitoring trends in burn severity", Fire Ecol, Vol. 3, pp. 3-21, 2007

(3) Hawbaker T, Vanderhoof $M$ and Beal $Y$ : "Mapping burned areas using dense time-series of Landsat data", Remote Sensing of Environment, Vol. 198, pp. 504-522, 2017

(4) Vanderhoof M, Fairaux N and Beal Y : "Validation of the USGS Landsat Burned Area Essential Climate Variable (BAECV) across the conterminous United States", Remote Sensing of Environment, Vol. 198, pp. 393-406, 2017

(5) Flood N, Danaher $\mathrm{T}$ and Gill $\mathrm{T}$ : "An operational scheme for deriving standardised surface reflectance from Landsat TM/ETM+ and SPOT HRG imagery for Eastern Australia”, Remote Sensing, Vol. 5, pp. 83-109, 2013

(6) Strahler A, Boschetti L and Foody G : "Global Land Cover Validation: Recommendations for evaluation and accuracy assessment of global land cover maps", GOFC-GOLD Report, No. 25, Joint Research Centre, European Commission, Ispra, Italy, 2006 